\title{
ACERCA DEL NOMBRE DEL RÍO ESLA Y OTROS CELTISMOS
}

El estudio del celta hispánico y el de los viejos nombres de río europeos son temas que en nuestro tiempo están a la orden del día. Un tomo dedicado a la memoria de un sabio que tanto se interesó por las viejas raíces de todo lo hispánico no es mal lugar para añadir otros casos a tan importantes legajos, y más si se trata del río más importante de los que cruzan la región leonesa (salvo el Duero, que sólo en pequeña parte es leonés).

Está claro que en esta zona no ha de extrañar un celtismo. Varios de los ríos vecinos, el Duero mismo, el Porma, el Duerna, el Vernesga, que baña la ciudad de León', probablemente el Órbigo, y más claramente todavía ríos poco más alejados, como el Arlanza, el $A$ lanzón y el Eresma ${ }^{2}$, llevan nombres de evidente entronque indoeuropeo, y por lo menos en parte céltico. Inmediato al curso del Esla se halla el célebre monasterio de Eslonza, del cual podemos decir lo mismo, aunque (pese a las apariencias) no debe de haber otra relación que ésta entre los dos nombres, pues Eslonza fue primitivamente A l is o n $\mathrm{t}$ i a ${ }^{3}$; a lo sumo es verosímil que a la transposición de Alsonza en Aslonza, Eslonza, ayudara el influjo de Esla.

1 Véase la etimología que indico en $Z R P h, 1961$, a propósito del libro de UlRICH SCHMOLL, Die Sprachen der vorkeltischen Indogermanen Hispaniens und das Keltiberische.

2 Se trata de * $\operatorname{Er} \breve{1} s \breve{a} m \breve{a}$ o* Ir $\breve{1} s a ̆ m a ̄$, cuyo aspecto céltico es inequivoco. Quizá un superlativo correspondiente al comparativo irl. ant. ire 'más largo', 'más allá' (indoeur. perios), aunque es prudente abstenerse de asegurarlo, pues en céltico mismo hay otras varias posibilidades. Pero desde luego hay que permanecer dentro de la serie numerosa de los superlativos célticos en - $\mathrm{s}$ a m a (Ledesma, Monesma, Luesma, Osma, fr. Molême, Angoulême, etc.).

${ }^{3}$ Para la terminación de este nombre, además de Tovar, Zeph, 8, 78-79, vćanse mis notas en $D C E C$, t. 4, p. $1012 a, 57$ ss., y en $H D A$, t. 1, 375-376. Para la raíz, $D C E C$, s. v. aliso. Aunque en la documentación medieval la forma Elisontia (año 912) está atestiguada algo antes que las formas en $\mathrm{Al}$ - y es más frecuente que éstas, como Alisonza se halla ya también desde 1050 (véase Menéndez Pidal, Origenes ${ }^{2}$, p. $317 ; R H i, 10,351,354,355$ ), es más convincente partir de Alisontia, teniendo en cuenta, no sólo la posibilidad de darle así una raíz y etimología razonables, sino el hecho de que esta base se halla de hecho documentada como étimo de varios ríos alemanes (Zeitschr. für Ortsnamenforschung, 4, 269 ss.; Zeilschr. für Celt. Philol., 21, 84; Rhein. Vierteljahrsblätter, 
Pero las formas antiguas del nombre de éste son muy diferentes: Estola en dos documentos del año 916 (España sagrada, t. 34, pp. 436, 441, apénd. 7 y 9), en otro de 1046 (Vignau, núm. 892) y en la Prim. crón. gen., $\$ 747$ ( ${ }^{\mathrm{a}}$ ed., p. $445^{b_{14}}$ ), Estula en un documento de 955 (Vignau, núm. 29), Extula en una nota en letra del siglo x (MEnÉNDEZ PIDAL, Origenes ${ }^{3}$, p. 25), y he visto más formas semejantes en otros documentos de la época; la sincopada Ezlla no parece hallarse antes de 1183 (M. Pidal, ibid., p. 247), y antes debió de pasarse por *Estla, que en boca de algunos llegaría a *Estra (cf. almendra a m y g d ă la), de donde una forma falsamente latinizada Estora, que no se encuentra más que en el Cronicón Albeldense ( $\$ 75$, Esp. sagrada, t. 18$)$, aunque el contexto de éste no deja dudas sobre la identificación. Ahora bien, la base E s t $\breve{u} \mathrm{l}$ a, que daba normalmente Esla en leonés y castellano, puede explicarse sin dificultad por el céltico, como veremos abajo.

Pero hay una cuestión previa. Varios eruditos han querido identificar el Esla con un río A s t u r a mencionado en época romana, y han dado a entender que este nombre sea el antepasado fonético de aquél, lo cual nos llevaría lejos de la etimología céltica. No hace falta ser muy sabio para ver que esta evolución fonética no es posible en Castilla la Vieja ni en León (si se tratara del Sur de España no podríamos decir tanto, pues un intermediario arabizado podría justificar así la $l$ como la $E$, pero estamos en el Norte de León, zona apenas hollada por musulmanes y sin arabización toponímica). Por lo demás, el vago parecido de los dos nombres era el único fundamento de la identificación, que tampoco puede apoyarse en la excepcional variante Estora del Albeldense. Pues sobre la localización del A s t ur a no tenemos más que indicios vagos; lo mencionan sólo dos fuentes, coincidentes ambas en relacionarlo con los Ástures, cuyo territorio se extendía, sí, hasta la cuenca alta del Esla, ya no a su parte

23, 9; KRAHE, $\left.B z N, 3,16_{5} s s.\right)$. Es curioso que por Eslonza pasa un pequeño río llamado Onza (MADoz), tributario del Esla. Sería natural la hipótesis de que Es lonza fuese primitivamente el nombre de este río, mutilado después, sea por haberse entendido Eslonza como es l'Onza 'es el Onza', sea por habérsele descompuesto en Esla Onza (como si dijéramos 'el segundo Esla, el llamado Onza'). - De una variante sufijal * A l is a n t ia (para esta terminación, véanse también mis notas citadas), que dio el nombre fluvial francés Auzance (A. Thomas, Revue Celt., 10, 22), debe de salir el nombre del río castellano Arlanza, puesto que era Aslanza o Aslança en 972 (M. Pidal, Origenes ${ }^{3}$, p. 66). En cambio, es bastante más dudoso que vayan con esta raíz y con el nombre del aliso los siguientes: Alesanco, cuya $e$ se aparta de la $i$ de aliso, y el mismo hecho de haber conservado la pretónica interna nos induciría a partir más bien de un * Ale $\mathrm{s}$ i a n k o - en relación con el famoso A l e s i a de la Côte d'Or; Aleje, partido de Riaño (Alexi en 958, Alece en 961: véase Vignau, fndice de documentos del monasterio de Sahagún), pues la vacilación entre $x$ leonesa y $c$ castellana sugeriría algo como*Ales-ci o*Al is-ci; Alija de los Melones, partido de la Bañeza (Alixa en 1235, VignaU; * A l ì c i a ?). 
baja, pero sobre todo coincidía con el actual principado de Asturias. Lo razonable es, pues, suponer que se tratara de uno de los tan numerosos ríos que cruzan esta provincia desde la Cordillera Cantábrica hasta el mar, varios de los cuales han cambiado radicalmente de nombre desde el tiempo de los romanos ${ }^{4}$.

En la sospecha de un origen céltico de Esla, E s t $\breve{\mathrm{l}} \mathrm{l}$ a , nos fortalece la localización de otros sitios de nombre igual o parecido. Hay una aldea Éstoa cerca de Mondoñedo, y otra de nombre Esto (o San Juan del Esto) junto a Carballo, 8 leguas al O. de La Coruña. Ahora bien, es sabido que '-o resulta normalmente de la evolución de '-oa en gallego, y éste a su vez es el resultado regular de la terminación - ŭ l a , luego ahí estamos también frente a la misma base Es t u la . Y desde luego, se sabe que Galicia es país tanto o más rico que León en celtismos.

Es posible y verosímil que antes existiera otro $\mathrm{Es} \mathrm{t} \breve{u} 1$ a hispano, a juzgar por el compuesto $\mathrm{E}$ s $\mathrm{t} \mathbf{l}$ e d $\mathrm{u} \mathbf{n ~ u ~} \mathrm{m}$. Podemos dar este nombre por documentado en la Bética y ya en la Antigüedad, pues un sepulcro hallado cerca de la villa de Luque, "en la cuesta de la fuente Alhama", nos conserva memoria de cierta dama llamada Fabia, que era Esttledunensis (CIL, II, 1601 $)^{5}$. Si el nombre del lugar presupuesto por este gentilicio es un compuesto de Est u la, esperaríamos, a la verdad, * E s t u 1 o d u n u m. Si la inscripción es algo tardía, de fecha ya visigótica, la alteración no ofrece la menor dificultad, pues se justifica tanto la disimilación o-U $>e-u$ como la síncopa, ya romance, de la $\mathbf{u}$ pretónica. Parece posible, sin embargo, justificar ambos cambios por hechos de fonética celtibérica, sobre todo el se-

4 San Isidoro (Etym., IX, 2, 112) se limita a decir que del nombre del Astura viene el de los ástures, "que viven a su alrededor cercados de grandes montañas y selvas". L. A. Floro (IV, 12) refiere que los ástures, en la batalla en que los vencieron los generales de Augusto, habían acampado junto al río Astura; agrega que los restos del ejército derrotado se hicieron fuertes más tarde en Lancia, pero no podemos asegurar que esta población se hallara cerca del mencionado río, ya que la acción segunda pudo no ser inmediata a la primera; además, la localización de Lancia es otra incógnita, que algunos, cayendo en un círculo vicioso, han querido despejar fundándose en la identificación, de puro sonsonete, entre el Astura y el Esla: así es como se ha supuesto que Lancia sea Mansilla la Mayor (no lejos del Esla). Si mis informes son completos, Lancia sólo figura por lo demás en Dión Casio, y luego en el Itinerario Antonino y en las Tablas de Tolomeo, pero tampoco estas fuentes bastan para localizarla, y por lo demás las dos últimas dan formas tan diferentes de ese nombre que ya no es seguro se trate de la misma población. Pero aun si otros datos o razonamientos confirmaran un día que el Astura es el Esla, tendría que tratarse del caso frecuente de un cambio total de nombre, pues no es posible fonéticamente pasar de A s t u r a a Esla.

5 Como el lapicida partió la palabra entre dos líneas detrás de la primera $t$, probablemente no hay que atribuir valor fonético a la duplicación de esta letra, a lo cual siempre puede ayudar el cambio de línea. A no ser que al escribir la segunda $t$ lo hiciera erradamente en vez de una $u$. 
gundo $^{6}$. Por lo demás, estos pormenores no oscurecen el punto fundamental: que se trata de un compuesto típicamente céltico, con el característico - $\mathrm{d}$ u $\mathrm{n} \mathrm{u} \mathrm{m}$, y formado sobre algo igual o muy análogo a Estula. Todo quedaría muy claro si es verdad que se trata, como informa HoLder (Altceltischer Sprachschatz), de un lugar llamado hoy Estola cerca de Luque, dato que por desgracia no he podido comprobar, ni averiguar su fuente, pese a mis esfuerzos ${ }^{7}$. Este nombre moderno puede resultar de un primitivo $E s t \breve{u} l$ a que coexistiera con el compuesto $\mathrm{Es}$ t l e d u n u m, ya sea por abreviación de éste, ya como forma primitiva del mismo, acaso el nombre de un riachuelo vecino, que serviría para bautizar el fuerte de E s$\mathrm{t}$ u l od u n u m, agregándole el nombre du num, que es genérico de 'fortaleza' en céltico.

Ahora bien, los celtas se extendieron asimismo por la Bética, aunque no en tan gran número como por Galicia y León, mas precisamente por esto tuvieron que fortificarse más; y aun quizá pueda hallarse algún indicio histórico de su relación con nuestro * E s t ulo d u n u m . Diodoro Sículo (25.10.1) nos ha transmitido la memoria de un general hispanocelta 'I $\sigma \tau$ тóárıos que luchó contra Amílcar en $23^{6}$ a.C. Como fue aliado de los tartesios, además de los iberos, cabe sospechar que perteneciera a los celtas béticos y que procediera de Estulodunum. Es sabido que la terminación -ates era muy viva en celta, lo mismo que en latín, para formar étnicos, y en aquella lengua había además una variante -atio-: luego no es arbitraria la idea de que Istolátios significase simplemente 'el de Éstula (=Estledunum)'s.

6 Véanse en el citado libro de Schmoll, p. 85, varios casos de síncopa comparables, y en la nota 4 de la p. 100 dos casos de asimilación vocálica análoga, aunque en verdad no bien seguros.

7 Don José M. Pabón, a quien me he dirigido en demanda de luces, me señala La Artola, nombre de un cortijo y caserio a 6.9 kilómetros de aquel pueblo, según el Nomenclátor oficial de 1863; habiendo amablemente escrito a sus corresponsales de Luque, le contestaron que hay en efecto un Cortijo Artola en el lugar llamado Montes de Luque y al pie de la "Piedra o Peña de Juan Mateo". Aunque no se han podido obtener más detalles, el señor Pabón, autoridad en toponimia andaluza, me escribe que cree posible el cambio de La Estola en La Artola; en efecto, st puede confundirse con $r t$ en la articulación de muchos lugares de aquella tierra, y todavía es más fácil pasar de $L a$ (E)st- a $L a A s t$, a condición, claro está, que el acento recaiga en la $\dot{o}$ y no en la inicial, como lo tenía E s t ŭ la: pero ni siquiera esto sería sin remedio en un territorio fuertemente arabizado; no siendo usual en árabe un tipo morfológico 'éstula pero sí 'astûla, el influjo de esta lengua pudo ser causante de esa alteración.

8 Para ejemplos análogos (aunque no estrictamente iguales) de ambos sufijos célticos, véanse Pedersen, V gl. Gramm., $\$ \$ 384$, 447, y Dottin, La langue gauloise, p. 110. La o primera de Istolátios se explicaría fácilmente como transcripción griega aproximada de una $u$ breve, especie fónica no existente en griego clásico (es sabido que así lo practicaban los griegos con muchos nombres latinos), y la I-, sea por algo análogo, o por algún fenómeno de tipo metafónico como los que tanto abundan en los dialectos célticos de todas las épocas. 
Admitida la verosimilitud general de un origen céltico de nuestra raíz toponímica, veamos de concretar su sentido y origen. El río Esla nace entre grandes montañas, en el extremo NE. de la provincia de León, concejo de Valdeburón, al pie de los montes de Tarna. En casi todo su curso pasa muy encajonado, hasta su desembocadura en el Duero, a medio camino de Zamora a la frontera portuguesa, pero a legua y media de su desagüe se precipita por una cascada muy conocida, "entre dos peñas de grande elevación cortadas casi perpendicularmente" (MADoz). Aunque éste es su salto más conocido, debe de haber otros muchos en su curso, pues Madoz, al describirlo, habla varias veces de "peñascos escarpados e inaccesibles". Pues bien, 'salto de agua' se dice ess en irlandés antiguo. $Y$ el caso es que esta base semántica puede convenir también a los tres homónimos hallados. En efecto, Éstoa se encuentra junto al río Bellegal, uno de los afluentes más altos del Miño, en país muy quebrado; y por Esto "baja" otro riachuelo a desembocar en el río Aliones, que cruza el país de Bergantiños. Este último nombre nos resulta elocuente por su evidente celtismo, y porque su étimo B riga n tes significa en celta 'montañeses': se trata, pues, en ambos casos de ríos de gran pendiente, en territorio muy montañoso, en los cuales no es de creer que falten saltos de agua. En fin, Luque está en la provincia de Córdoba junto al límite de Jaén y no lejos del de Granada, en un paraje donde hay sierras que exceden en mucho de los 1000 metros; y aunque no he podido lograr detalles de la situación de Estola ni E s t l e d u n u m, recuérdese que el sepulcro está en la "cuesta" de una fuente, y que el cortijo La Artola radica en los Montes de Luque y al pie de una "Peña" conocida: luego no es improbable que haya por allá algún salto de agua.

El irl. ant. es(s) es palabra bien conocida: WINDrsch (Irische Texte mit Wörterbuch) la documenta traduciéndola 'Wasserfall', y O'Rerlly vierte eas (la forma tomada por ess en irlandés moderno) como 'cataract'. Hoy, según O'Grady, es muy empleado sobre todo en la toponimia irlandesa. Su etimología indoeuropea es algo menos segura: WALdE-PoKorny lo analizan como un *PED-TU-, de la raíz

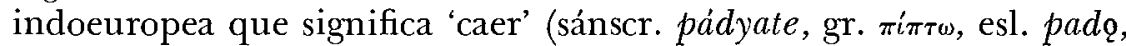
angls. feta, II, 24; LEW, II, 294, 296), lo cual no ofrece dificultad alguna en cuanto a las consonantes, y tampoco parece chocar con tropiezos graves en los aspectos vocálico y morfológico; sin embargo, algunos especialistas han pensado en otros étimos, si bien se trata, al menos en parte, de opiniones que parecen anticuadas. De todos modos, el aspecto de ess es arcaico, y la ss es resultado normal en irlandés de un grupo más antiguo sт (que puede o no venir de T'т o D’T); este grupo se conserva siempre en britónico, y en galo aparece unas veces como sT y otras como Ts, sin norma bien averiguada (cf. Pedersen, I, pp. $79,80,136$, y por otra parte $\$ \$ 252-253$ ). Como el 
celta de España coincidía muchas veces con el galobritónico, y además era mucho más arcaico que éste y que el irlandés, es de creer que si la palabra que nos interesa existió en hispanocéltico, tendría la forma * e st u s. Ahora bien, un derivado * Es t ŭ $1 \bar{a}$, con terminación adjetiva, cuadraba bien a un curso de agua muy pendiente y caracterizado por sus saltos ${ }^{9}$.

Joan Corominas

The University of Chicago. Institut d'Estudis Catalans.

- La E hispanocéltica, aunque breve, era cerrada, y cuando tónica daba $e$ sin diptongo en castellano, según dejé probado en la Zeitschr. f. Celt. Phil., 25, p. 53; cf. Festschrift Rohlfs, 1958, p. 100. Los celtismos vascos bost y masusta, el cast. ambuesta y el cat. embosta son testigos de la conservación de sT en el celta peninsular. Verdad es que otras formas, como almorzada, mayueta y el cat. maduixa, indican que el paso a $\mathbf{T s}(>\mathbf{T H})$ se producía en otras hablas locales célticas. Pero la toponimia es por lo general más conservadora que los apelativos, así que todo nos conduce a esperar la conservación de -sT- en los nombres que nos interesan. 